\title{
Quality over quantity: a necessary path for clinical research transformation in China
}

\author{
Da Xu, Bao-Cai Xing \\ Key Laboratory of Carcinogenesis and Translational Research (Ministry of Education/Beijing), Hepatopancreatobiliary Surgery Department I, \\ Peking University Cancer Hospital \& Institute, Beijing, China \\ Correspondence to: Bao-Cai Xing, MD. Key laboratory of Carcinogenesis and Translational Research (Ministry of Education/Beijing), \\ Hepatopancreatobiliary Surgery Department I, Peking University Cancer Hospital \& Institute, 52 Fucheng Road, Haidian District, Beijing, China. \\ Email: xingbaocai88@sina.com.
}

Submitted Aug 21, 2020. Accepted for publication Aug 31, 2020.

doi: $10.21037 / \mathrm{hbsn}-2020-5$

View this article at: http://dx.doi.org/10.21037/hbsn-2020-5

Since the Chinese economic reform in 1978, its medical field has made remarkable progress in the past 40 years. In most medical fields, China's diagnosis and treatment methods are comparable to the international high standards. In recent years, with the continuous expansion of the medical research team and the improvement of laboratory research equipment and methods, China has achieved some influential and internationally recognized research outcomes. However, overall, China still lags behind developed countries in terms of high-level original medical research, especially in high evidence-based medical research (1).

China has a large population base, and the number of cases is among the highest in the world. If Chinese doctors can make full use of these patient resources, it would be very beneficial to conduct research on disease pathogenesis and diagnosis and treatment. However, many clinical studies currently focus on quantity rather than quality, so it is difficult to obtain research results that can change clinical practice. There are subjective and objective factors leading to this situation. What is the future of clinical research in China? This question will be discussed from the following four aspects.

\section{Clinical research training for young clinicians}

A big issue with Chinese clinicians is that many of them have not received standardized clinical research training and they lack the basic skills to conduct clinical research. To change this situation, it is necessary to emphasize the importance of cultivating scientific research thinking, methods, and awareness in young clinicians in the process of clinical medical education. Clinicians need to improve their clinical research literacy because it helps to solve clinical problems and it prompts the development of modern medicine. Only when clinicians have scientific research capabilities such as literature retrieval and reading, topic selection and research design, data analysis, and maintaining enthusiasm as well as sensitivity to scientific research in clinical work, can clinicians consciously discover problems in their work and design standardized research for clinical problems. Besides, in China, the number of articles is often associated with the professional development of clinicians in most of the medical institutions, which leads clinicians to publish as many articles as possible, regardless of the quality of the articles. The management department of medical scientific research ought to reinforce their communication with front-line clinicians, devoting more efforts on improving the scientific research ability of clinical researchers. They could also provide financial supports and preferential policy based on the needs of clinicians, solve the problems encountered by clinical researchers in their research, and proactively held more clinical research training courses related to the clinical scientific research project application. For those who have innovative ideas and some advantageous departments, the hospital can also give them more support to help conducting high-level clinical research smoothly. 


\section{Innovations in clinical research}

A large number of clinical studies are published in China every year, but many studies are still blindly following the trend, simply repetitive, and lack originality and innovation. After having good scientific research training and awareness, Chinese clinicians could make good use of our large patient resources, taking advantage of our valuable clinical experience, and exploring novel and significant clinical research problems in our daily work. The most important thing is to focus on how to solve clinical problems. Clinicians should have the courage to discover scientific problems in the clinic, read the literature extensively, actively explore new technologies and methods based on the research progress, design rigorous prospective or retrospective multi-center studies for verification, obtain high-level evidence-based medicine, and eventually rewrite the guidelines and consensus. In daily work, we could actively "bring in and go out", building scientific research communicate platform, actively communicating with domestic and international high-level centers, broadening our horizons and understanding the frontiers of domestic and foreign research, so that we can integrate our research with the international hotspots. In addition, for clinical problems, clinicians need to see through the appearance to perceive the essence, combining scientific research with clinical practice. We can actively cooperate with basic medical researchers to explore mechanisms to better explain the occurrence and progression of diseases (2).

\section{Establishment of the clinical research platform}

At present, many Chinese clinical studies have included a large number of cases, but their clinical information is not comprehensive. Some of the research conclusions drawn are relatively simple, which cannot form highlevel evidence to change the guidelines. The reason is due to the lack of a thorough clinical database. Establishing an integrated clinical research platform and database is a long and difficult accumulation process, but it is the only way for clinical research to go from simple repetition to high-level research. This integrating process requires a group of people with good team spirit, long-term data accumulation, and a long-term vision for designing leading medical research. Of course, a good research platform also requires the concerted efforts of pathology, radiology, ultrasound and other disciplines to work together to ensure the integrity and standardization of the research database to the greatest extent. Therefore, scientific research requires solid data accumulation in order to gain high-level research results. Up to now, many Chinese clinicians have made good examples in the development of clinical database and performing highlevel scientific research. Wei et al. published a randomized controlled trial (RCT) on preoperative radiotherapy for resectable hepatocellular carcinoma (HCC) with portal vein tumor thrombus based on their database of HCC, combining with several other centers (3). He et al. reported the results of their center, by conducting an RCT study of hepatic arterial infusion combined with sorafenib versus sorafenib alone for the treatment of HCC patients with portal vein invasion (4). These highquality researches have been recognized and praised by international peers for the rigorous design, detailed data analysis and solid results of the study, which is possible to rewrite the guidelines.

\section{Obligation in clinical research}

In China, although medical development has reached a high level in recent years, it is still far from meeting people's needs, and there are still many unresolved problems in clinical practice. Clinicians should have a sense of obligation, not only do their best to relieve the pain of patients but also actively identify and try to find ways to solve the existing problems in current clinical diagnosis and treatment process. Just as we said in the Hippocratic Oath, "as long as my life endures, may I commit myself to advance the nation's medical science and research as well as the well-being of the entire buman race" (5).

Publishing high-level articles is not the only purpose of conducting clinical research. More importantly, we hope the research could solve practical problems in the clinic, so that more patients can receive more beneficial standardized treatment. With this sense of obligation in clinical research, clinicians can change their mindset from passively conducting research to actively exploring problems, and only then can they obtain more innovative, high-level research outcomes that truly solve clinical problems.

For a long time, the development of clinical medical research in China has been mainly focused on quantity of the research (6). However, we should admit that western clinicians have long been playing main role in evidencebased clinical guideline making. It is quite difficult for Chinese scholars, which are non-native English speakers to report their results and publish research in high-level 
journals to gain wide recognition from Western countries. Indeed, clinical research in China has made great progress in recent years. We have also gradually overcome the difficulties in hardware and caught up in the amount of research. The government and scientific research institutions also made great efforts to encourage scientific research innovation and the output of scientific research results, which had formed a superior scientific research atmosphere. Many of the importance research results has been recognized and accepted by worldwide academic community. The prior experiences set the foundation for the discovery of new findings in future development. Transformation of clinical research from quantity to quality is a long and necessary process. With the improvement of our understanding, future clinical research will definitely move towards high-quality, innovative research and solve the real problems for patients in China.

\section{Acknowledgments}

Funding: This study was supported by grants from the National Nature Science Foundation of China (No. 81874143 ) and the Beijing Natural Science Foundation (No. 7192035).

\section{Footnote}

Provenance and Peer Review: This article was commissioned by the editorial office, Hepatobiliary Surgery and Nutrition. The article did not undergo external peer review.

Conflicts of Interest: Both authors have completed the ICMJE uniform disclosure form (available at http://dx. doi. org/10.21037/hbsn-2020-5). The authors have no conflicts of interest to declare.

Ethical Statement: The authors are accountable for all aspects of the work in ensuring that questions related to the accuracy or integrity of any part of the work are appropriately investigated and resolved.

Open Access Statement: This is an Open Access article distributed in accordance with the Creative Commons Attribution-NonCommercial-NoDerivs 4.0 International License (CC BY-NC-ND 4.0), which permits the noncommercial replication and distribution of the article with the strict proviso that no changes or edits are made and the original work is properly cited (including links to both the formal publication through the relevant DOI and the license). See: https://creativecommons.org/licenses/by-nc-nd/4.0/.

\section{References}

1. Gao R, Liao Z, Li ZS. Scientific publications in gastroenterology and hepatology journals from Chinese authors in various parts of North Asia: 10-year survey of literature. J Gastroenterol Hepatol 2008;23:374-8.

2. Ba DN. We should pay more attention on clinical research. Zhonghua Yi Xue Za Zhi 2003;83:1-2.

3. Wei X, Jiang Y, Zhang X, et al. Neoadjuvant ThreeDimensional Conformal Radiotherapy for Resectable Hepatocellular Carcinoma With Portal Vein Tumor Thrombus: A Randomized, Open-Label, Multicenter Controlled Study. J Clin Oncol 2019;37:2141-51.

4. He M, Li Q, Zou R, et al. Sorafenib Plus Hepatic Arterial Infusion of Oxaliplatin, Fluorouracil, and Leucovorin vs Sorafenib Alone for Hepatocellular Carcinoma With Portal Vein Invasion: A Randomized Clinical Trial. JAMA Oncol 2019;5:953-60.

5. Markel H. "I swear by Apollo"--on taking the Hippocratic oath. N Engl J Med 2004;350:2026-9.

6. Goh KL, Farrell GC. Publications from China: the sleeping giant awakens. J Gastroenterol Hepatol 2008;23:341-3.
Cite this article as: Xu D, Xing BC. Quality over quantity: a necessary path for clinical research transformation in China. HepatoBiliary Surg Nutr 2020;9(5):684-686. doi: 10.21037/ hbsn-2020-5 